Session TC2-3

\title{
Development of Mixed Signals Course for Electrical Engineering Technology Program
}

\author{
Mohan Ketkar \\ Engineering Technology Department \\ Prairie View A\&M University
}

\begin{abstract}
One of the important components in the criteria for accreditation of engineering technology programs is to demonstrate continuous improvement. This can be achieved by various ways such as by updating the list of required courses by adding new courses or revising contents of existing courses. Every program needs to keep up with current trends in the industries and job market to produce technologists with needed preparation. Considering expectations from Electrical Engineering Technology graduates, we developed a new course covering topics in mixed signals. This junior level course is complemented by a laboratory course consisting of experiments to perform testing of mixed signals and devices. During fall 2008 this course was offered as special topics. Subsequently this course will be converted in to a regular numbered course in the electrical engineering technology degree plan. Funding for development of the course and laboratory was obtained from the department of education. The laboratory equipment includes LAB-View ${ }^{2}$, MATLAB $^{3}$ software and NI ELVIS ${ }^{4}$ hardware interface. The assessment of both lecture course and laboratory was performed keeping in mind TAC-ABET outcomes. This paper describes the outline of the mixed signal course and various experiments developed for mixed signals testing. Student learning expectations are also presented.
\end{abstract}

\section{Introduction}

Continuous improvement is one of the important components in the criteria for accreditation of engineering technology programs. This can be demonstrated by various ways such as by updating the list of required courses by adding new courses or revising contents of existing courses. At individual course level instructors assess their courses and design a plan for implementation during next time offering. Every program needs to keep up with current trends in the industries and job market and review its focus and content every few years. The degree plans for engineering technology programs at PVAMU have had no major upgrading done in over ten years. The department started deliberating for revamping of its two programs last year. A departmental curriculum committee was formed to look at engineering technology degree requirements at PVAMU compared with several other universities granting similar degrees. A draft plan was formulated. This included addition of several new courses as well as renaming many courses updated with new topics. The number of total credit hour is also being reduced to align with national average. So now the process has started and will go through appropriate reviewing at various levels in the College and the University.

Proceedings of the 2009 ASEE Gulf-Southwest Annual Conference Baylor University

Copyright (C) 2009, American Society for Engineering Education 
One of the areas where increasing demand for Electrical Engineering Technology graduates is Mixed Signal Testing in Semiconductor manufacturing industries. Several discussions with industrial partners revealed that engineering technology graduates are most appropriate for this type of fast paced demanding and highly paid profession, Test Engineer. These graduates have necessary fundamentals in electrical engineering and plenty of hands-on experience in laboratories. Based on the discussions with Industrial Advisory Board it was decided to develop a course to provide students with advanced knowledge and laboratory experience in the mixed signals testing area.

A proposal for funding for development of courses and laboratory facility for mixed signals and digital signal processing was submitted to the Department of Education under Title III. This was funded last year and all the equipment and software necessary for the laboratory was acquired during summer of 2008. The development of mixed signal courses was accomplished during the summer and was offered as Special Topics in Mixed Signals in fall 2008. The revamped degree plan proposal for engineering technology degrees includes this course and associated laboratory.

\section{New Course}

The course level chosen is at the junior level in the second semester with 3 credit hours and corequisite laboratory with 1 credit hour. Students are expected to have background of DC/AC circuits, electronic devices, and digital fundamentals through pre-requisite courses at freshman and sophomore levels. Since the first two years of both electrical engineering technology and computer engineering technology at Prairie View A\&M University are identical, the mixed signal course is available to computer engineering technology majors also. For computer engineering technology majors this course can be counted as one of the technical electives requirement for graduation.

\section{Lecture Course}

Considering the needs for test engineering following topics are considered for the lecture course. The overview of mixed signals highlighting the key components of testing are presented at the beginning.

1. Overview of Mixed-Signal Testing

2. The Test Specification Process

Generation of test programs from data sheets

Test program structures and functionality

3. DC and Parametric Measurements

Continuity, leakage, offset, gain, and PSRR

4. Measurement Accuracy

Absolute accuracy, resolution, software calibration, standards traceability, and measurement repeatability

5. Tester Hardware

Generic mixed-signal ATE tester

6. Sampling Theory

ADC and DAC sampling theory

Proceedings of the 2009 ASEE Gulf-Southwest Annual Conference Baylor University

Copyright (C) 2009, American Society for Engineering Education 


\section{Analog Channel Measurements}

Basic AC channel tests

\section{Adoption of TEXT}

Most appropriate text for the lecture course is 'Introduction to Mixed-Signal Test and Measurement' by Burns and Roberts ${ }^{1}$. Topics for the lecture course are very much in line with the chapter sequence in the adopted text. In addition several references are utilized to complement the text with latest trends.

In the pre-requisite courses students are exposed to electrical measurements during laboratory courses. They are familiar with basic connections and set up, however the depth in accuracy, reliability, repeatability, and error issues are not stressed in freshman sophomore courses. In this course those are introduced with emphasis on automated measurement considerations. Another important aspect is reading and understanding device data sheets. Based on the published data some approaches to develop and design a test plan are discussed. Students are also exposed to sampling theory and its relation to more advanced automated test systems. The assignments include application of fundamental circuit laws and error analysis to solve practical problems.

This course at this time is used as a technical elective for existing degree plan, however later will be identified as required course in the new proposed curriculum revision.

Assessment of the following course objectives are carried out from the accreditation point of view.

[b] an ability to apply current knowledge and adapt to emerging applications of mathematics, science, engineering and technology

[f] an ability to identify, analyze and solve technical problem

Course Grading Policy: Student's final course grade is based on three components, homework, tests and final exam. The percent distribution is given below.

$\begin{array}{ll}\text { Homework } & 30 \% \\ \text { Two Tests (20\% each) } & 40 \% \\ \text { Final Examination } & 30 \%\end{array}$

\section{The Laboratory Course}

One credit hour laboratory course meets once a week for 3 hours. Most of the experiments are performed as a team of two students. Few assignments are performed individually. The topical list of experiments is:

1. Familiarization of the Lab Equipments, Safety and Review of Lab-VIEW

2. $\quad$ Remotely Controlled equipments such Digital Multi-meter, Function Generator, DC Power Supply and Oscilloscope using Lab-VIEW

3. Testing of Diodes, Transistors and Op-amps using Lab-VIEW 
4. Testing of Transistors using Lab-VIEW

5. $\quad$ Testing of Op-amps using Lab-VIEW

6. Testing of comparators using Lab-VIEW

7. Utilizing MATLAB for sampling and analysis of waveforms

All students are required to write individual reports in a standardized format and submitted after completion of each experiment. The grading and assessment for following ABET outcomes for this course is performed in accordance with all college assessment policies.

[c] an ability to conduct, analyze and interpret experiments and apply experimental results to improve process

[g] an ability to communicate effectively - Ability to organize, plan and properly format a written technical report

Sample report cover pages are attached in the Appendix which makes is easier for the instructor to have course assessment reports ready shortly after end of the semester.

Laboratory Course Grading Policy: Student's final course grade consists of three parts report, participation and final exam.

$\begin{array}{ll}\text { Lab reports } & 60 \% \\ \text { Participation } & 20 \% \\ \text { Final Examination } & 20 \%\end{array}$

\section{Laboratory Facilities}

As mentioned earlier that the laboratory equipment was funded by the Title III project. We have ten workstations each equipped with set of test equipment and a PC. Related software installed on the PCs includes Lab VIEW and MATLAB along with Microsoft Office. The test equipment set consists of arbitrary waveform generator, power supply, and NI ELVIS.

\section{Summary}

In summary, based on the needs of the semiconductor industry we have developed a new course and associated laboratory in area of the mixed signals testing for electrical engineering technology students. The course addresses various key issues in the testing and measurement. Students perform experiments in the newly equipped laboratory. Assessment of both lecture and lab are done based on the TAC-ABET outcome criteria.

\section{References}

1. Burns and Roberts, "Introduction to Mixed-Signal Test and Measurement” Oxford Univ. Press, New York, Nov. 2000

Proceedings of the 2009 ASEE Gulf-Southwest Annual Conference

Baylor University

Copyright (c) 2009, American Society for Engineering Education 
2. Lab VIEW http://www.ni.com/labview/

3. MATLAB http://www.mathworks.com/products/matlab/

4. NI ELVIS http://www.ni.com/nielvis/

MOHAN A KETKAR

Dr. Ketkar is an Associate Professor and Co-coordinator of Electrical Engineering Technology program at the Prairie View A\&M University, TX. He received his M.S. and PhD in Electrical Engineering from the University of Wisconsin-Madison. He has served as faculty member at Lake Superior State University, MI, University of Houston and Prairie View A\&M University. He is a member of the Departmental and College Committee for ABET and member of College curriculum committee at PVAMU.

Proceedings of the 2009 ASEE Gulf-Southwest Annual Conference

Baylor University

Copyright (C) 2009, American Society for Engineering Education 
Appendix 1

PRAIRIE VIEW A\&M UNIVERSITY

DEPARTMENT OF ENGINEERING TECHNOLOGY

Fall 2008 Semester

\section{ELET4101 Special Topics Mixed Signals Laboratory}

Last Name

First Name

\section{Laboratory Exercise Number}

Date Assigned:

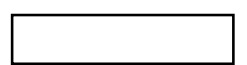

Date Due:

Title of the laboratory exercise

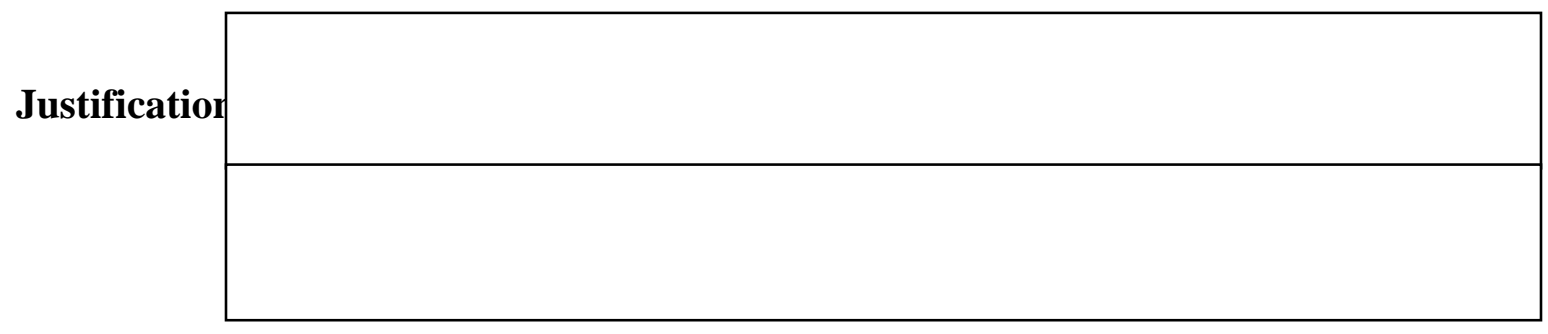

\begin{tabular}{|c|c|c|}
\hline TAC/ABET Outcome Assessment & Points & Score \\
\hline $\begin{array}{l}\text { Outcome 'c' An ability to conduct, analyze and interpret } \\
\text { experiments and apply experimental results to improve process } \\
\text { Sub-Outcome c.2 Ability to conduct experiments }\end{array}$ & 50 & \\
\hline $\begin{array}{c}\text { Outcome 'g' An ability to communicate effectively } \\
\text { Sub-Outcome e.1 Students follow formal report format }\end{array}$ & 50 & \\
\hline
\end{tabular}




\section{Outcome c}

Assignment Statement: This segment of the assignment measures An ability to conduct, analyze and interpret experiments and apply experimental results to improve process - Outcome [c]. The Sub-Outcome statement is

Sub-Outcome c.2

Ability to conduct experiments

Instructions:

Place your work (lab datasheet) after this page. 


\section{Outcome g}

Assignment Statement: This segment of the assignment measures the ability of the students to work in teams - Outcome [g]. The Sub-Outcome statement is

Sub-Outcome e.1

Students are able to provide written report of the experiments conducted.

\section{Instructions:}

1. Place your formal report after this page 